\title{
Analysis of the Effect on Moral Education Exerted by Peer Groups Among College Students
}

\author{
Min SONG \\ - $\quad{ }^{1}$ School of Humanities and Economic Management, School of Marxism, \\ China University of Geoscience, Beijing, China. \\ songmin@cugb.edu.cn
}

Keyword: students, peer group, moral education

\begin{abstract}
To perform moral education targeted at college students, attention should be paid to the existence of peer groups and the study of its role as well as function so as to give play to its positive effects. In addition, on the basis of respect and understanding, peer group should be made as an important medium for students' self-taught and also an effective platform for moral education through the development of group culture and cultivation of group core people, etc. Colleges and universities have always laid great emphasis on the moral education towards college students. To make moral education effective, educators should first gain their psychological acknowledgment and raise emotional resonance to satisfy their inner needs, and the peer groups, prevalent in colleges and universities, are able to provide psychological satisfaction and acknowledgment since interpersonal code of conduct, value, moral identity are more easily accepted among peer groups in colleges and universities, where the students' values and behavioral patterns are consistent with the group and it will play a significant role in their moral development.
\end{abstract}

\section{Traits of Peer Groups in Colleges and Universities}

A peer group is comprised of people with relatively equivalent social standing and of the same age. In this paper, a peer group among college students means a spontaneously-formed non-official group made up of young college students who are bonded with emotional relationship, who share the same interests, hobbies, values and code of conduct, and who have frequent communication and interaction among each other. It is an importance environment for their growth and development, an important place for their moral cognition and moral experience, also a piece of land for their moral practice. Values and code of conduct among peer groups can exert unconscious influence on the socialization and moral development of the teenagers and advance their development regarding emotion, cognition and the ability of morality practice. The traits of peer group and its significant influence on moral formation can be demonstrated in the following aspects:

\section{Leaders are Included in Peer Groups, who Play Core Roles}

Non-official leaders in peer groups refer to those who serve as the heads in the group. Those people may not either be nominated and dispatched or elected but have great influence in the group, play a leading role for other members and have bigger say in group decisions. Equipped with more outstanding abilities than other members generally, non-official leaders direct the group by naturally-established authorities among members. They are expert in observing and adjusting group atmosphere and maintaining members' interests, whose view of life, value system, morality and conduct will serve as guidance for other members and would be emulated by others, consequently greatly influence the development of individual ideology and morality within the group.

\section{A Peer Group is Spontaneously Formed with Relatively Strong Cohesiveness}

Establishment of a peer group is the result of free combination among college students in accordance with their own wills, who share common hobbies, common experience, common needs and common cultures. All of these make these young people foster a sense of emotional acknowledgment and psychological reliance. According to the Stage of Moral Development theory 
by Kohlberg, a prominent psychologist in the United States, teenagers entering higher education is in the stage of social covenant and ordinary moral principle orientation. Therefore, peer groups take an eminent position in the establishment of moral cognition and values for college students. For them, peer groups are where they can perceive and experience morality.

\section{Members in Peer Groups Enjoy Equal Standing and Close Interactions}

Members of college student peer groups are featured by relatively equal interpersonal relationships. In the group, each member has a tiny space of his own and all people are in a relatively equal footing, jointly constituting a stable social network. Members among the same peer group can share information, help each other and become friends following the same path and sharing common ideals. As a non-official group, it negatives institutionalized interpersonal relationships but cherishes mutual emotion bonds, so it needs no power to make interference. Equal membership combined with intimate relationships interrelates with each other, forming a survival environment for peer group members. Conferred with equal and democratic atmosphere in peer groups, teenagers experience development in their ability of subjective judgment, accelerate their transformation from external control to self-discipline, and also enhance the ability of morality practice.

\section{Analysis of Effect on Moral Cultivation Exerted by Peer Groups among College Students}

The presence of peer groups satisfies the needs of college students psychologically and emotionally, gives members a sense of belonging and security through group interaction, and has a significant impact on the views of life, values and ethical behavior of its members. College students learn how to get along with people in groups, which is an inevitable process before they enter the adult community. To first become a qualified member of the group, and then of the community; this is the logical development of young people's moral development.

\section{The Crowd Mentality among Group Members Provides A Prerequisite for Morality Development}

Crowd mentality refers to a kind of psychology that individuals are inclined to external effects and demonstrate behavioral patter conforming to public opinions or the majority's viewpoints. Characteristic of strong cohesiveness and high homogeneity, members in peer groups are prone to crowd mentality. None of us excludes the need for security and belonging. Therefore, to obtain psychological security, individuals choose to follow the trend in order to avoid loneliness, frustration and other negative emotions resulting from isolation. Therefore, individuals are likely to comply with value system and behavioral pattern in group. Group members always take their leaders as examples by imitating their behavioral styles and learning from their moral traits like honesty, magnanimity and optimism. And through mutual learning and mutual influence, members in peer groups become convergent in their ideology and behavior, thus making these moral ideas, value systems and behavioral patterns fixed and transmitted within the peer groups. As a result, group members will conform to these values. Certainly, crowd mentality can have dual effect on moral development. On the one hand, members are able to learn social norms; on the other hand, college students may acquire ill-natured ideology or habits blindly when following the trend, which consequently influencing individual moral development.

\section{The Peer Group Satisfies College Students' Demand for A Sense Of Belonging and Security}

Since college students are not financially independent of their parents' support, their conduct will undoubtedly be restrained by their parents at home and regulated by teachers within campus. Such external control conflicts with their inner desire for independence and freedom, so the feeling of depression and loneliness constantly afflicts these young people, pushing them to find their own shelters. Under such condition, the peer group, completely belonging to the young people, provides them with satisfaction and desirable experience. Young people within peer groups will perform social comparison, which is a basic starting point for peer communication since they need 
affirmation for self-value and establishment of security via social comparison. A sense of belonging arises through the youth's communication, activities and cultural identity within peer groups. These young people tend to demonstrate their self-value by playing a certain role in the peer group and unbosoming their vexation to obtain emotional comfort. Hereby, the peer group has not only satisfied the youth's need but also won their hearts.

\section{The Peer Group Will Have Impact on Teenagers' Value Systems and Behavioral Patterns.}

Owing to mutually frequent contact and mutual trust among members in peer groups accompanied by their compatibility in mentality and emotion, they are prone to accepting mutual influence. Opinions from peer groups increasingly take priority when the youth are setting living goals and value systems. Peer groups among young people are the aggregation of frequent contact featured by wide interaction range and mutually emotional appeal and psychological allusion. In peer groups, people will unconsciously think and act in consistence with common ways within the groups. In other words, the young people have been infused with group values and behavioral patterns. It is noted on the surface level that members within the same peer group display similarity in their attire and dressing styles and some groups even present conspicuous external marks. With deeper observation, we can find that peer group members are similar in terms of behaviors, interests and hobbies, thinking patterns and consumption habits. Because the young in general concern a lot about peer's comments on them and hope to be embraced by group members to gain satisfaction and happiness, they will take the initiative to emulate other members and therefore easily absorb in the group's value systems and behavioral patterns.

\section{Countermeasures to Bring Moral Education among College Students in Peer Groups into Function}

Moral education targeted at college students should not only lay great emphasis on explicit education channels like classrooms, political parties and other organizations, classes and student organizations but also incorporate peer groups into moral education cause to exploit implicit education's advantage into full play and ultimately establish a new education mode combined by both explicit and implicit lessons. By guiding a healthy development of peer groups, we want to make it a crucial approach for moral education towards college students and implement moral education towards college students by fully exploiting peer group’s traits.

\section{Show Sufficient Respect and Understanding to Peer Groups among College Students}

During the implementation of moral education, moral educators would by no means gain desirable results without full understanding and respect of the learning subject. Moral educators must show acknowledgment and respect to peer groups in colleges and universities and cannot ignore or easily negate these groups since every college student will join in one or more peer groups to satisfy their demand for emotion and interests. On the basis of respect, educators are supposed to take the initiative to understand these groups and know their group objectives, member composition plus activity routines. If change permits, educators should also have frequent communication with group members, understand their latest ideas and strike genuine conversations with them. If possible, moral educators can provide them with some support within their capacity, win group members' trust. Especially group leaders and deliver the signal of understanding, respect and acceptance. Such understanding and respect to students is the basis for the implementation of moral education.

\section{Take Full Consideration to the Traits of Sub-Culture among Different Peer Groups and Implement Oral Education Specifically}

The emergence of sub-culture in groups among college students poses both new venue and challenges for moral education in colleges and universities. With the advent of sub-culture in groups among college students, moral educators have no choice but to accept that it is a new phase in which group culture has become a part of social and cultural environment. Therefore, they have 
to fully evaluate and understand the effects and restrictions on group members exerted by such cultural background. Sub-culture traits of different groups should also be taken into account to fully exploit and develop the potential moral education value of peer groups. Group sub-culture is, in nature, an intermediary agent influencing moral education result, which can deliver processed culture to group members. Moral educators in colleges and universities should take the guidance of cultural construction in peer groups as a priority and take non-compulsive measures to exert indirect effects by adhering to the principle of tolerance and understanding. Moral education is wide in its content and range, so it is impossible for peer groups to absorb in all contents. Educators ought to bring the limited effect and function of peer groups among college students into play according to their types and traits. Moral educators must be aware of such limitation and always conform to the principle of "doing something and refraining from doing other things". Peer groups can have enormous influence on college students' socialization, value system, the perfection of personality and other aspects, somoral educators must take this trait into account, actively leading college students to be syntonic and gregarious, helping them to learn interpersonal communication and team cooperation and also enhance their establishment of desirable moral traits like collectivism, integrity, respect for others and self-discipline.

\section{References}

[1]ZhangXuxin, Dilemma and Reflection of Contemporary Moral Education [J].Studies in Ideological.2013.1

[2]Yuan Guilin, Western Moral Education Theroy[M].Fujian Education Press..2005.5 